\title{
A STUDY TO ASSESS THE EFFECTIVENESS OF BATES THERAPY ON VISUAL ACUITY AMONG ELDERLY IN A SELECTED OLD AGE HOME AT ALAPPUZHA DISTRICT
}

\author{
Mrs. Sajeena. U*, Mrs. Rekha. S** \& Mrs. Evangilene. J** \\ *Student of Josco College of Nursing, Edappon, Mavelikara, Kerala, India. \\ **Professor \& HOD of Medical Surgical Nursing, Josco College of Nursing, Edappon, Mavelikara Allapuzha, Kerala, India. \\ ***Professor and Principal, Josco College of Nursing, Edappon, Mavelikara, Alapuzha, Kerala, India. \\ DOI: http://doi.org/10.47211/tg.2020.v07i03.012
}

\section{ABSTRACT}

A pre experimental study was conducted to assess the effectiveness of Bates therapy on visual acuity among elderly in a selected old age home at Alappuzha district. The objectives of the study were to assess the mean pretest and posttest level of visual acuity among elderly, to find out the effectiveness of Bates therapy on visual acuity among elderly, to find out the association between pretest level of visual acuity and selected socio demographic variables. One-group pretest posttest only design was selected for the study. The sample composed of 33 elderly people with visual problems, selected by non-probability purposive sampling technique. The conceptual framework of the study was Roy's Adaptation Theory. Bates therapy was administered to the experimental group daily for duration of 30 minutes for 26 days. In the right eye the number of positive differences 30, and zero differences 3. After dropping the zero differences, with number of samples $n=30$, the obtained $p$-value is 0.00000000931 with $P<0.001$ level of significance whereas in the left eye the number of positive differences 29 and zero differences 4 . After dropping the zero differences, with number of samples $n=29$, the obtained P-value is 0.00000000186 with $p<0.001$ level of significance. Hence we can conclude that the Bates therapy was effective in improving visual acuity. There was no significant association between pretest level of visual acuity with selected socio demographic variables.

Keywords: Effectiveness; Elderly; Bates therapy; Visual acuity; Old age home.

\section{ABOUT AUTHORS:}

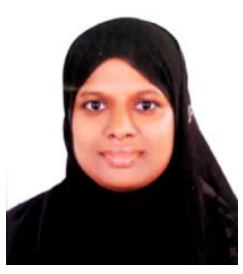

Mrs. Sajeena. U is student of Josco College of Nursing, Edappon, Mavelikara, Kerala, India. She has attended various national, international conferences and work shop.

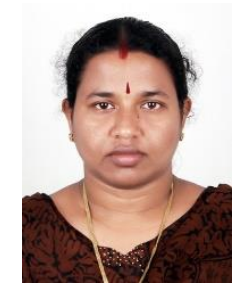

Mrs. Rekha. S, Professor and HOD of Medical Surgical Nursing, Josco College of Nursing, Edappon, Mavelikara Allapuzha, Kerala, India. She has presented various conferences and work shop.

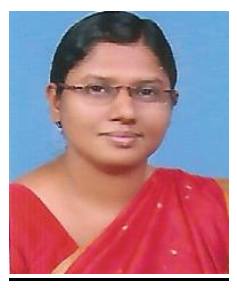

Mrs. Evangilene. J is Professor and Principal, Josco College of Nursing, Edappon, Mavelikara, Alapuzha dist, Kerala, India. She has published various research papers and attended national and international conferences and workshops. 


\section{INTRODUCTION}

The eye is the window of the human body through which it feels its way and enjoys the beauty of the world. The eye is not only the most beautiful but also the most important sensory organ of human body and vision is one of the most wonderful gifts. Moreover, the eyes make an essential contribution to the facial expression and serve for getting contact with the other people. Therefore they are indispensable means of communication. But as age raises elderly people develop visual problems by showing the symptoms like blurred vision, visual defect, fore sight and short sight, which blocks the beauty of eye sight.

Ageing is the journey or maturation. The process of ageing classically depicted as one of the constant and inexorable decline often reaching a peak of bodily function efficiency around the end of second decade of life. In India it is reported that at present there are 77 million elderly persons and the number is expected to be 177 million in the next two decades. According to WHO, $81 \%$ of all people who are blind or have moderate to severe vision impairment are aged 50 years and above. With an increasing population of older people, more people will be at risk of vision impairment due to chronic eye diseases. Vision loss among the elderly is a major health care problem. Approximately one person in three has some form of vision-reducing eye disease by the age of 65 . The most common causes of vision loss among the elderly are age-related macular degeneration, glaucoma, cataract and diabetic retinopathy. Eye exercises are one of the most useful non pharmacological techniques for ocular strengthening and improve vision. Prevailing modality of treatment should be supplemented by some ocular strengthening therapy by which ocular health can be maintained and promoted. Search for such modality lead the investigators to Bates Eye exercise therapy, which is under evaluated by modern science. However it is practiced in full pledged manner in many reputed institutes of India like School for perfect eyesight at Pondicherry and Moraji Desai institute of Yogic Science at New Delhi.

\section{Need and significance of the study}

Visual impairment is a global public health challenge affecting over 285 million people worldwide, including 39 million blind. The world health organization reported that every minute somewhere in the world one goes blind. For most of them, there is no curative treatment of the underlying pathology. The research both from India and other parts of the world has revealed that visual impairment increases with increasing age. It is also estimated that people aged 50 years and older comprise $65 \%$ and $82 \%$ of the total visually impaired and blind, respectively. Studies have also shown a higher prevalence of visual impairment in elderly people living in nursing homes compared with those living in non-institutionalized settings. Possible reasons for this include poor awareness by professional care givers of resident's visual function, visual status, need for spectacles or ocular disease or lack of referral. Even if referral is done unless measures are taken to facilitate the process, the uptake of services is reported to be low.

Research on vision and aging is essential for several reasons. The percentage of the population in the United States and many other countries over age 60 is increasing, and thus eye conditions, diseases and vision impairments associated with aging represent a larger segment of our societal health challenge on a population basis than in previous decades. Thus, there is a pressing need to identify the prevalence and incidence of various aging-related vision impairments in populations, the mechanisms underlying these impairments, and how they impact older adult's performance of everyday visual tasks. India is witnessing a demographic transition with an increasing proportion of older individuals with increased life expectancy. The social structure too is changing from joint families to nuclear families. Owing to these changes, there is a likelihood that the proportion of elderly people living in old age home may increase to proportions seen in developed countries today.

\section{Statement of the problem}

A study to assess the effectiveness of Bates therapy on visual acuity among elderly in a selected old age home at Alappuzha district.

\section{Objectives of the study}

The objectives of the study were;

1. To assess the mean pretest and posttest level of visual acuity among elderly.

2. To find out the effectiveness of Bates therapy on visual acuity among elderly.

3. To find out the association between pretest level of visual acuity and selected Socio demographic variables.

\section{HYPOTHESIS}

$\mathrm{H}_{01}$ : There is no significant difference in mean posttest level of visual acuity among elderly after practicing Bates therapy.

$\mathrm{H}_{1}$ : There is a significant difference in mean posttest level of visual acuity among elderly after practicing Bates therapy.

$\mathrm{H}_{02}$ : There is no significant association between pretest level of visual acuity and selected demographic 


\section{ARTICLES}

variables.

$\mathrm{H}_{2}$ : There is a significant association between pretest level of visual acuity and selected demographic variables.

\section{Assumptions}

The study assumes that:

\section{Variables:}

Bates therapy may be effective in increasing visual acuity among elderly.

Socio demographic variables

In this study, socio demographic variables which includes age, gender, religion, type of family, education, previous occupation, dietary pattern, use of spectacles, most frequent activity that cause pain in your eyes, the factor which is most commonly causing allergy in your eyes, activity that mostly contribute to watery eyes, most frequently occurring eye problems, eye sight problem that mostly affect your daily activities, duration of eye disorders, most affected co-morbidity, condition in which you mostly use eye drops, most frequently occurring infection in your eyes, an injury that mostly affected your eyes, interval of eye checkup, difficulties in performing daily activities due to visual problems, main problem that affect your eye lids, main source of information regarding management of visual problems.

\section{Dependent variable}

Visual acuity of elderly was the dependent variable.

Independent variable

Bates therapy was the independent variable in the present study.

REASEARCH METHODOLOGY

Research approach: Quantitative approach.

Research design: Pre experimental one group pre-test posttest only design.

Setting of the study: St. Mary's Daya Bhavan, Kollakadavu.

Population:

Target population: Elderly people

Accessible population: elderly people with visual acuity $\leq 6 / 9$ either in one or both eyes.

Sample size: 33

Sampling technique: Non probability purposive sampling technique

Tools and technique:

Tool 1: Socio demographic proforma.

Technique: Structured interview schedule.

Tool 2: Snellen chart.

Technique: Bio physiologic technique.

Reliability of Tool

The reliability of the Snellen chart is $p<0.001$. The prepared tool was administered to 10 elderly with visual acuity $\leq 6 / 9$ in Shalem Bhavan, Mavelikara for establishing the reliability of the instrument. The

$P$ value was calculated and found that $p<0.001$. This indicates that the tool was highly significant and reliable for the present study.

\section{Conceptual framework}

Roy's Adaptation Model 1989.

Inclusion criteria

Elderly those who are:-

- Having visual acuity $\leq 6 / 9$.

- In the age group of 60 years and above.

- Able to comprehend the instructions.

- Available during data collection.

- Willing to participate in the study.

- Both male and female.

Exclusion criteria:

Elderly those who are:-

- Having visual acuity 6/6.

- Having any pathological eye condition like glaucoma, cataract etc.

- Having any cranial nerve problems in the eyes which restrict to practice Bates therapy.

- Having any eye injury. 


\section{ARTICLES}

- Presently doing any other eye exercise.

- Under treatment for any eye problems.

- Not willing to participate in the study.

\section{Data Collection Process}

\section{Step 1}

For conducting main study, researcher obtained permission from concerned authorities in St. Mary's Daya Bhavan, at Alappuzha district. The data collection period from 01/12/2017 to 30/12/2017.

\section{Step2}

Visual assessment done for the participants on 01-12-2017.

Step 3

Informed consent and socio demographic data was obtained from 33 participants those who have visual acuity $<6 / 9$ either in one eye or both eyes on 02-12-2017.

Step 4

Bates therapy demonstrated to all 33 samples on 03-12-2017.

Step 5

Bates therapy practiced by the samples for duration of 30 minutes once daily as three sessions, 11 members in each from 4-12-2017 to 29-12-2017 under the supervision of the researcher for 26 days.

Step 6

Posttest conducted for all the 33 samples on 30-12-2017.

Descriptive statistics

Frequency and percentage distribution were used to describe the socio demographic variables.

Inferential statistics.

Sign test, Chi-square test.

Section I: Distribution of subjects according to the socio demographic variables.

- $42.4 \%$ of the samples were in the age group of $60-70$ years.

- $60.6 \%$ of the samples were females.

- $69.7 \%$ of the samples were Hindu.

- All $100 \%$ of the samples belonged to nuclear family.

- $69.7 \%$ of the samples educated up to high school.

- $40 \%$ of the samples were unemployed

- A vast majority $93.9 \%$ of the samples were non vegetarian

- $42.4 \%$ of the samples were not using spectacles.

- $60.6 \%$ of the samples never feel pain.

- $93.9 \%$ of the samples had no allergy.

- $60.6 \%$ of the samples had no watery eyes.

- $39.4 \%$ of the samples had watery eyes.

- All $100 \%$ of the samples had long sightedness.

- $30.3 \%$ of the samples had eye disorders for 2-3 years.

- An equal proportion of the samples $36.4 \%$ had no co- morbidity and had diabetes mellitus

- $75.8 \%$ of the samples were not using eye drops.

- All $100 \%$ of the samples had no eye infection.

- All $100 \%$ of the samples had no eye injury.

- $75.8 \%$ of the samples had never performed eye checkup.

- $78.8 \%$ of the samples had never experienced difficulties in performing daily activities due to visual problems.

- All $100 \%$ of the samples had no eyelid problems.

- $72.8 \%$ of the samples had no information regarding management of visual problems. 


\section{ARTICLES}

Section II - Assessment of pretest level of visual acuity of right age elderly in a selected old age home at Alappuzha district.

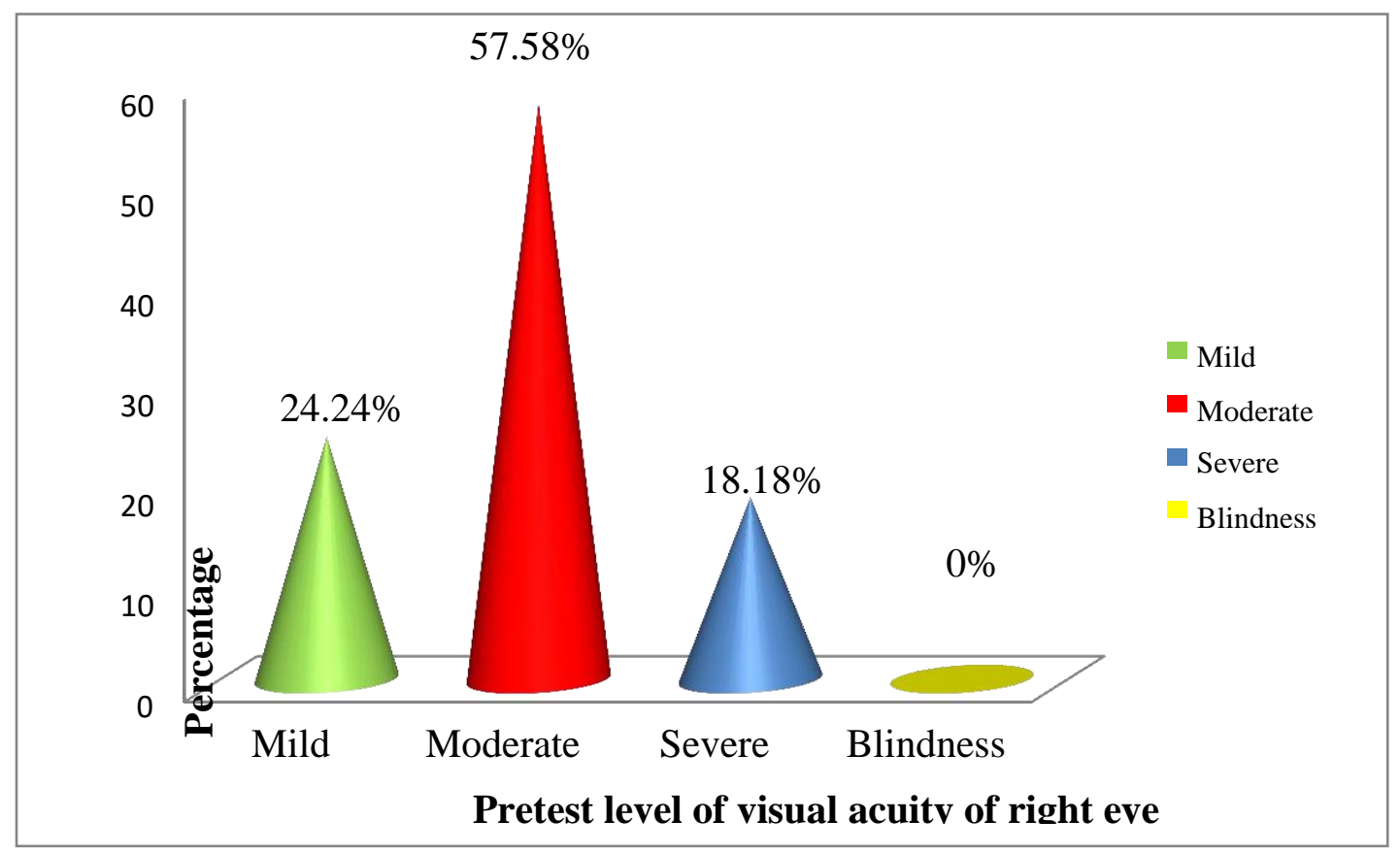

Cone diagram showing percentage distribution of samples based on pretest level of visual acuity of right eye.

Assessment of posttest level of visual acuity of right eye among elderly in a selected old age home at Alappuzha district.

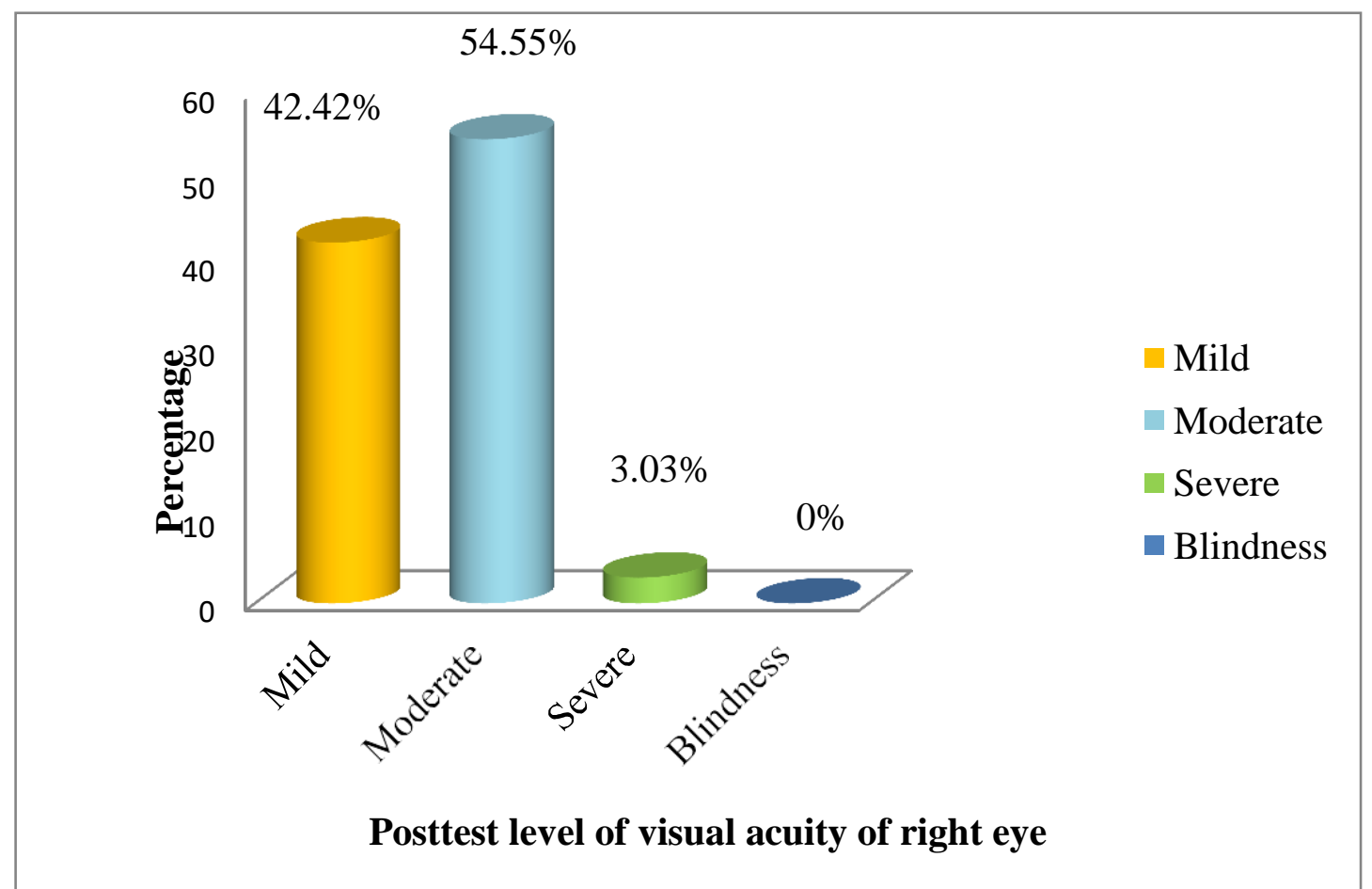

Comparison of pretest and posttest level of visual acuity of right eye among elderly in a selected old age home at Alappuzha district. 


\section{ARTICLES}

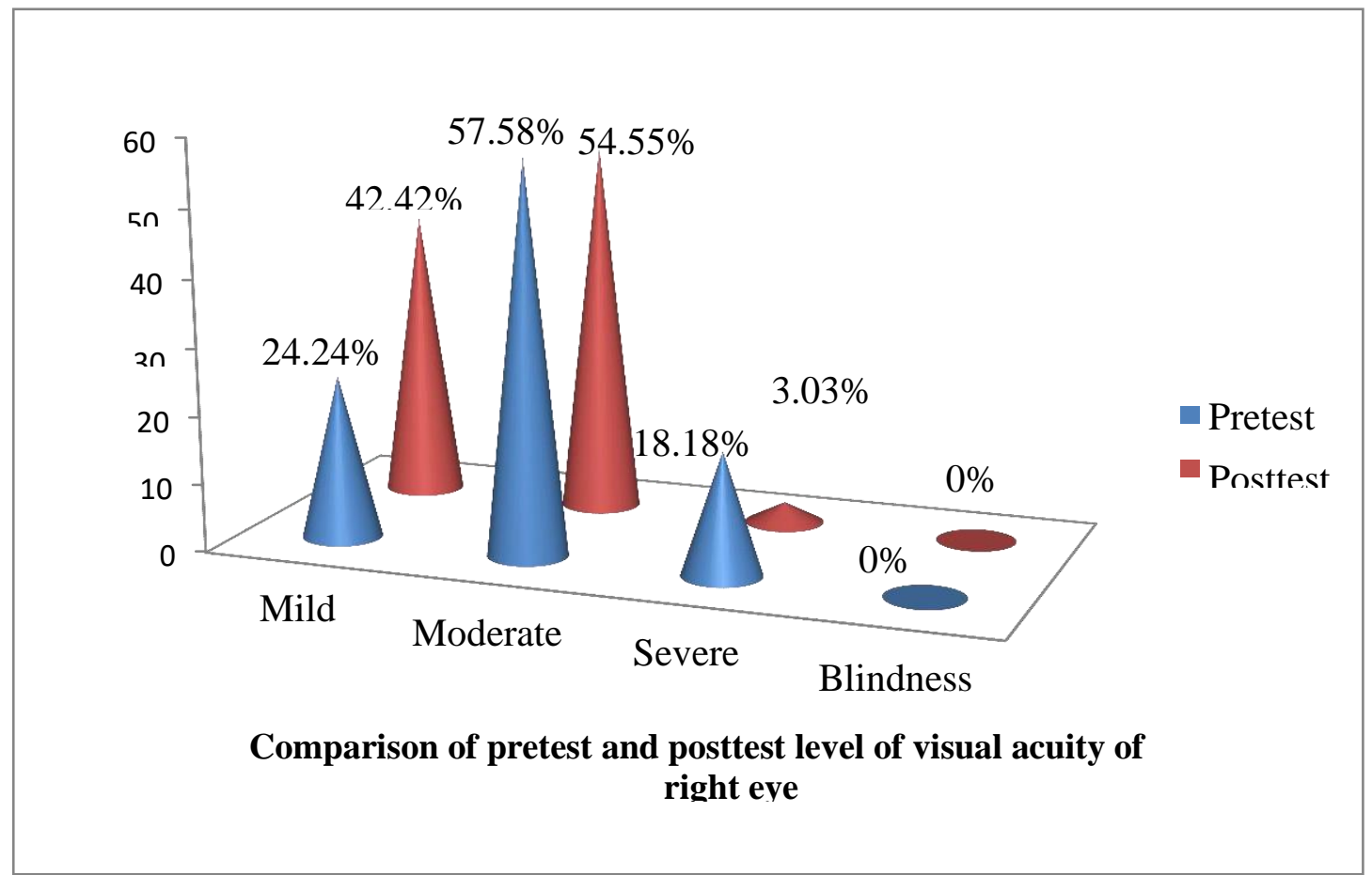

Assessment of pretest level of visual acuity of left eye among elderly in a selected old age home at Alappuzha district.

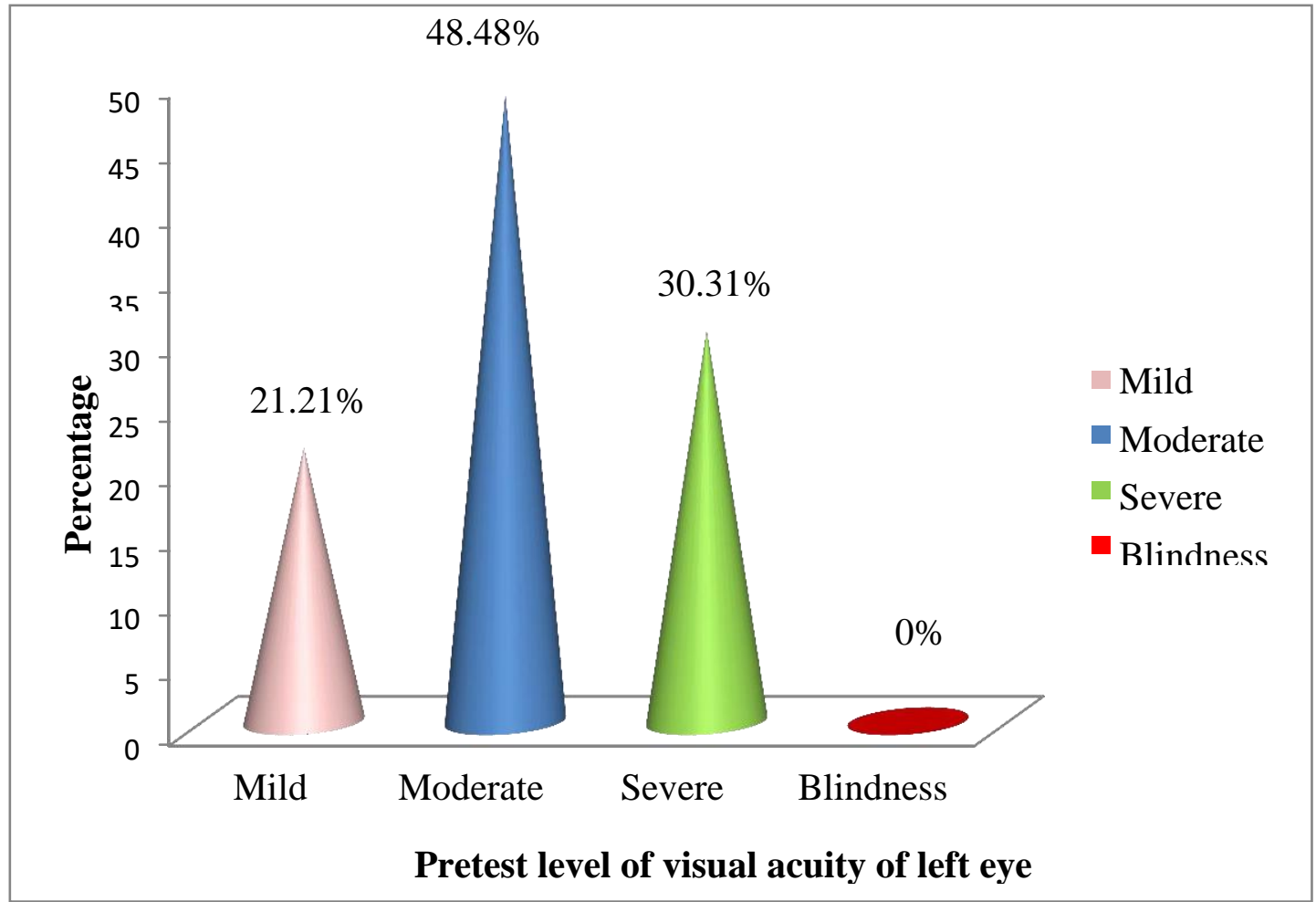

Cone diagram showing percentage distribution of samples based on pretest. 


\section{ARTICLES}

Section III: Assessment of posttest level of visual acuity of left eye among elderly in a selected old age home at Alapuzha district.

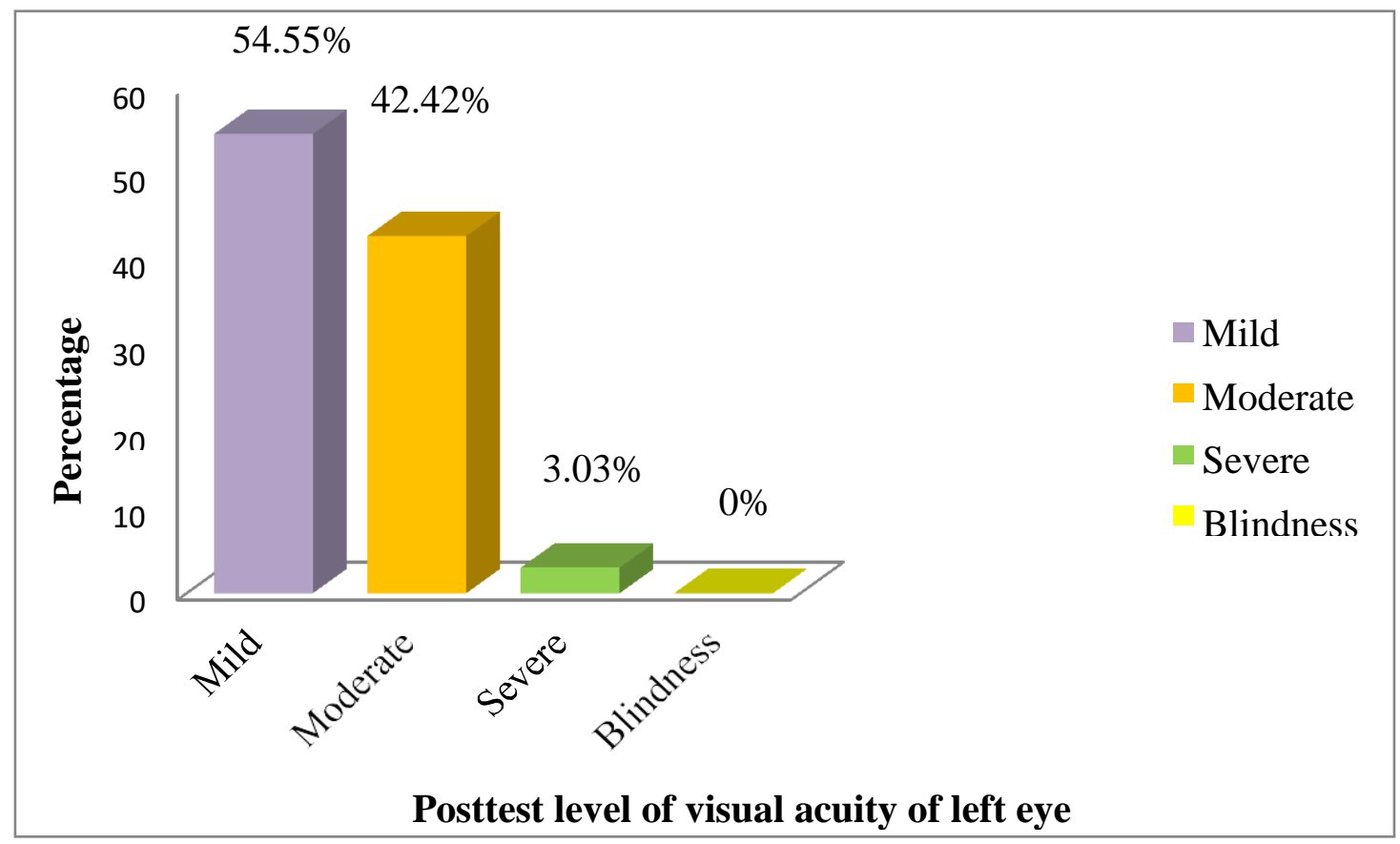

Bar diagram showing posttest level of visual acuity of left eye among elderly in a selected old age home at Allapuzha

Section IV: Comparison of pretest and posttest level of visual acuity of left eye among elderly in a selected old age home at Alappuzha district.

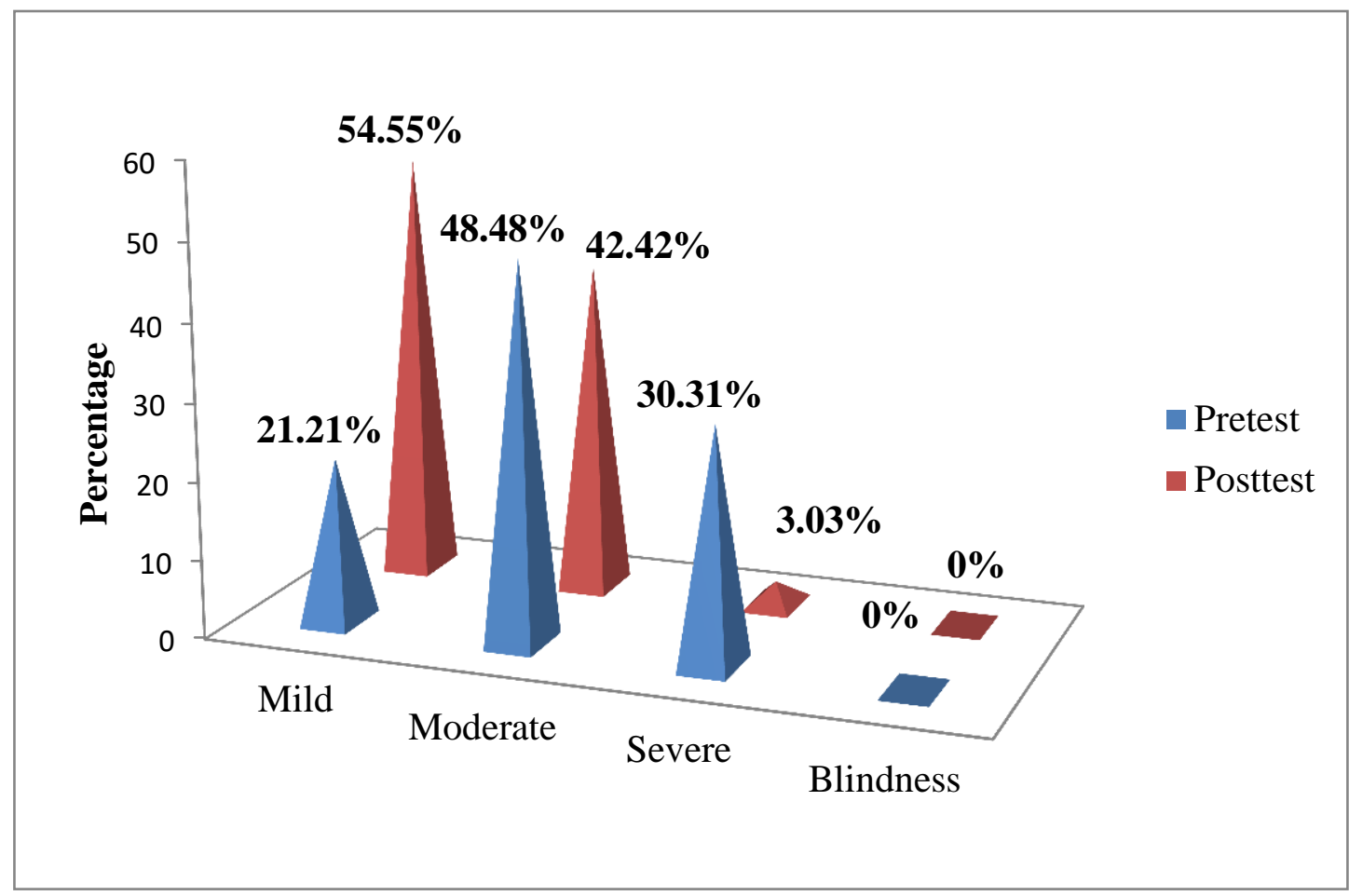

Cone diagram showing pretest and posttest level of visual acuity of left eye among elderly in a selected old 
Section V: Analysis of the effectiveness of Bates therapy on visual acuity among elderly in a selected old age home at Alappuzha district.

Sign test was used to assess the effectiveness of Bates therapy on visual acuity among elderly. After practicing Bates therapy, in the rights eye the number of positive differences 30 and zero differences 3 . After dropping the zero differences, with number of samples $n=30$, using sign test, the obtained $P$ - value is 0.00000000931 with $p<0.001$ level of significance, whereas in the left eye the number of positive differences 29 and zero differences 4. After dropping the zero differences, with number of samples $n=29$, using sign test, the obtained $\mathrm{P}$ - value is 0.00000000186 with $\mathrm{p}<0.001$ level of significance. Therefore the null hypothesis $\mathrm{H}_{01}$ was rejected and research hypothesis $\mathrm{H}_{1}$ was accepted. The study concluded that, there was a significant difference in the level of visual acuity after practicing Bates therapy.

Section VI: Association between the pretest level of visual acuity and selected socio demographic variables.

Pretest level of visual acuity and selected socio demographic variables such as age, gender, religion, type of family, education, previous occupation, dietary pattern, most frequent activity that cause pain in your eyes, the factor which is most commonly causing allergy in your eyes, activity that mostly contribute to watery eyes, most frequently occurring eye problems, eye sight problem that mostly affect your daily activities, duration of eye disorders, most affected co-morbidity, condition in which you mostly use eye drops, most frequently occurring infection in your eyes, an injury that mostly affected your eyes, interval of eye checkup, difficulties in performing daily activities due to visual problems, main problem that affect your eye lids, main source of information regarding management of visual problems.

Association between pretest level of visual acuity and selected sociodemographic variables.

Chi-square test was used to determine the association between pretest level of visual acuity and selected socio demographic variables such as age, gender, religion, type of family, education, previous occupation, dietary pattern , most frequent activity

that cause pain in your eyes, the factor which is most commonly causing allergy in your eyes, activity that mostly contribute to watery eyes, most frequently occurring eye problems, eye sight problem that mostly affect your daily activities, duration of eye disorders, most affected co-morbidity, condition in which you mostly use eye drops, most frequently occurring infection in your eyes, an injury that mostly affected your eyes, interval of eye checkup, difficulties in performing daily activities due to visual problems, main problem that affect your eye lids, main source of information regarding management of visual problems.

The calculated Chi-square value was less than the table value at $p<0.05$ level of significance for all socio demographic variables. Hence the null hypothesis $\left(\mathrm{H}_{02}\right)$ can be accepted and research hypothesis $\left(\mathrm{H}_{2}\right)$ can be rejected. So it can be concluded that there was no significant association between pretest level of visual acuity with selected socio demographic variables.

\section{RECOMMENDATIONS}

A similar study can be conducted in a large sample for wider generalization

An experimental study can be conducted with control group.

A comparative study can be conducted between Bates therapy and other alternative therapies. 


\section{ARTICLES}

\section{CONCLUSION}

The Bates eye method is an alternative therapy to cure defective eyesight and diseases of the eye by means of specific exercises. Using eye exercises is a powerful component of a whole system of small lifestyle changes that have been shown to improve eyesight naturally

\section{REFERENCES}

1. Paulo Coelho. Quotable Quote. Manuscript Found in Accra. [Cited May 2016]. Available from: https://www.goodreads.com/quotes/857760-the- eyes-are-the-mirror-of-the-soul-and-reflect.

2. Leonard Slain. Leonardo's Brain: Understanding Da Vinci's Creative Genius. [Cited 2014]. Available from: https://books.google.co.in/booksisbn.

3. Dr. Shilpa Anup Dhote. Eye exercises an eyesight rejuvenation therapy. World Journal of pharmaceutical research. [Cited 2015]. Available from: http://www.wjpr.net

4. The Eye/Clinical characteristics: Augenklinik Stralsund. 24 April 2015.

5. Prof.N.Sheelavathy. Effectiveness of Bates therapy on visual problems among elderly. [Cited April- June 2016]. Available from: International journal of advances in nursing management.

6. World Health Organization. Blindness and visual impairment. [Cited 2017].

Available from: http://www.who.int/news-room/fact-sheets/detail/blindness- and-visual-impairment.

7. David. A. Quillen. Common causes of vision loss in elderly patients. (Cited July 1999) Available from https://www.aafp.org/afp/1999/0701/p99.html 